\title{
ASPECTS OF CLINICAL FEATURES, DIAGNOSIS, NOTIFICATION AND TRACING BACK REFERRING TO TRICHINELLA OUTBREAKS in North Rhine-Westphalia, Germany, 1998
}

\author{
NOECKLER K.*, REITER-OWONA I.**, HEIDRICH J.*, PROTZ D.*, REHMET S.***, SINN G.** \& AMMON A.***
}

\begin{abstract}
Summary :
52 cases of human trichinellosis were notified from 11 towns in North Rhine-Westphalia from November 1998 to March 1999 After non-typical symptoms in the enteral phase, fever, muscular ache, headache, oedema, disorder of vision and rash occurred in the parenteral phase. Trichinellosis was serologically confirmed by ELISA, IFAT or western blot. Raw sausage and minced meat produced from raw pork could be determined as probable source of infection with 44 and eight notified cases, respectively. Whereas questionable raw sausage was not available for examination, frozen minced meat from the second outbreak could be secured in households of infected people. Larvae were isolated from minced meat and were identified by PCR as Trichinella spiralis. Tracing back to the source of infection was difficult because of the long time between clinical symptoms, laboratory diagnosis and notification as well as complex trade routes for pork and its products. Trichinella cases emphasize the necessity to meet the prescribed slaughter inspection and to guarantee a reliable prove of origin for meat products especially in view of specific consumer habits, i.e. the consumption of raw meat.
\end{abstract}

KEY WORDS : human trichinellosis, clinic, diagnosis, notification, tracing back.

I n Germany, human trichinellosis is a fairly rare disease. There are 0 to 10 notified cases per year which are mostly imported from Eastern Europe. From 1965 to November 1998, three outbreaks were registered in Germany (Table I). Experience from these outbreaks demonstrated that health risks for consumers arise if the meat contaminated with Trichinella larvae is not correctly examined for the muscle parasites or is not frozen alternatively according to methods prescribed in the Directive 77/96/EEC and if the meat is consumed in a raw or insufficiently treated condition as minced meat or sausage. According to the Interna-

\footnotetext{
* Federal Institute for Health Protection of Consumers and Veterinary Medicine (BgVV), Diedersdorfer Weg 1, 12277 Berlin, Germany. ** Institute for Medical Parasitology, Rheinische Friedrich-WilhelmsUniversität, Siegmund-Freud-Str. 25, 53105 Bonn, Germany.

*** Robert Koch Institute, Stresemannstrasse 90-102, 13302 Berlin, Germany.

Correspondence: Dr. K. Noeckler, Federal Institute for Health Protection of Consumers and Veterinary Medicine, Diedersdorfer Weg 1, 12277 Berlin, Germany.

Tel.: +49-188-8412 2053 - Fax: +49-188-8412 2000

E-mail: k.noeckler@bgvv.de
}

\begin{tabular}{cccc}
\hline Year & $\begin{array}{c}\text { Location } \\
\text { (Federal land) }\end{array}$ & $\begin{array}{c}\text { Number } \\
\text { of cases }\end{array}$ & $\begin{array}{c}\text { Source of infection } \\
\text { (Reference) }\end{array}$ \\
\hline 1967 & $\begin{array}{c}\text { Diez } \\
\text { (Rhineland-Palatinate) }\end{array}$ & 278 & $\begin{array}{c}\text { Pork, minced meat } \\
\text { (Anders } \text { et al., 1969) }\end{array}$ \\
1977 & $\begin{array}{c}\text { Ebermannstadt } \\
\text { (Bavaria) }\end{array}$ & 69 & $\begin{array}{c}\text { Wild boar meat, raw sausage } \\
\text { (Teuber } \text { et al., 1979) }\end{array}$ \\
1982 & $\begin{array}{c}\text { Bitburg } \\
\text { (Rhineland-Palatinate) }\end{array}$ & 408 & $\begin{array}{c}\text { Pork, raw sausage } \\
\text { (Stein, 1983) }\end{array}$ \\
\hline
\end{tabular}

Table I. - Trichinella outbreaks in Germany from 1965.

tional Commission of Trichinellosis (ICT), 791 human cases were reported by the EU members of the ICT in 1998 due to the consumption of pork, wild boar or horse meat in France, Germany, Italy and Spain (Dupouy-Camet, 1999).

Together with the Robert Koch Institute (RKI), the Institute for Medical Parasitology (IMP) and local veterinary and health authorities, the National Veterinary Reference Laboratory for Trichinellosis (NVRL) of the $\mathrm{BgVV}$ took part in the investigations on human trichinellosis cases in the federal land North Rhine-Westphalia (NRW) at the end of 1998.

\section{CLINIC, DIAGNOSIS AND NOTIFICATION}

total of 52 Trichinella cases was notified from
11 towns in NRW from November 1998 to
March 1999. 47 people had clinical symptoms over a period of nine weeks from 6 October to 8 December 1998 with a peak in the fourth week of October. Five non-symptomatic cases were diagnosed serologically by retrospective examinations. In the enteral phase which lasted until the 2nd to 3rd week of infection in most cases, more or less atypical symptoms like diarrhoea and stomach-ache occurred. In the parenteral phase, clinical symptoms like muscular ache and oedema were more characteristic symptoms for trichinellosis (Table II).

Trichinella cases were diagnosed between 12 November 1998 and 20 February 1999 on the basis of clinical symptoms, eosinophilia and the detection of specific 


\begin{tabular}{llcc}
\hline \multicolumn{1}{c}{ Phase } & \multicolumn{1}{c}{$\begin{array}{c}\text { Number } \\
\text { of } \\
\text { cases }\end{array}$} & Percentage \\
\hline Enteral phase & Stomach ache & 18 & $38,3 \%$ \\
& Sickness & 14 & $29,8 \%$ \\
& Diarrhoea & 11 & $23,4 \%$ \\
Parenteral phase & Vomiting & 1 & $2,1 \%$ \\
& Muscular ache & 36 & $76,6 \%$ \\
& Fever & 33 & $70,2 \%$ \\
& Headache & 26 & $55,3 \%$ \\
& Muscular weakness & 15 & $31,9 \%$ \\
& Oedema (extremities) & 12 & $25,5 \%$ \\
& Oedema (face) & 11 & $23,4 \%$ \\
& Rash & 11 & $23,4 \%$ \\
\hline
\end{tabular}

Table II. - Main clinical symptoms of 47 Trichinella cases in NRW.

Trichinella antibodies with IFAT, ELISA or western blot. Muscle biopsies taken from two patients about 10 days after the onset of clinical symptoms were negative. Most serum samples of patients were sent to the $\mathrm{BgVV}$ for re-testing sera with an ELISA based on an excretory-secretory (E/S) antigen from Trichinella spiralis. Titres for Anti-Trichinella-IgM and -IgG ranged from 1:80 to $1: 1280$ and from 1:80 to 1:2560, respectively. In some cases Anti-Trichinella-IgM titres were higher than -IgG but in no case -IgM antibodies could exclusively be detected. Results of comparative studies conducted at the IMP with the IFAT demonstrated a high correlation to the results of E/S-ELISA.

According to the German legislation, trichinellosis is a notifiable disease in case of illness or death. Trichinella cases in NRW were notified over a period of 14 weeks from 24 November 1998 to 5 March 1999 to the local health authorities which informed the local veterinary service for tracing back measures.

\section{TRACING BACK}

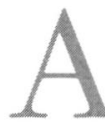
ccording to results of a case control study conducted by the RKI, two different sources were identified (Rehmet et al., 1999). 44 Trichinella cases were traced back to raw sausage 'Mettwurst' which is a traditional product in Germany and was made of fresh pork neck from Spain and frozen pork belly from Germany and Belgium.

Besides, there were eight people in the town Mettmann-Langenfeld who did not eat such raw smoked sausages but consumed minced meat made of fresh pork (from several companies in Belgium, Netherlands and Germany) and beef. All the minced meat was bought in the same supermarket. Frozen samples of minced meat could be collected in two households where clinical trichinellosis appeared. Trichinella larvae were detected in one sample of minced meat with the magnetic stirrer method which was carried out according to Council Directive 77/96/EEC. Larvae were genotyped by PCR as Trichinella spiralis at the Reference Center for Trichinellosis, Istituto Superiore di Sanità in Rome, Italy. Tracing back to the animal farm was not possible due to the complex trade routes and the partial lack in animal marking. Random samples of raw smoked sausages and minced meat which were produced later by the same manufacturers proved to be Trichinella negative.

\section{DISCUSSION}

$\mathrm{R}$ esults of investigations on Trichinella outbreaks in NRW demonstrate the closed connection between and problems which arise for the tracing back from the questionable food to the animal farm on the other hand. Due to the fact that human trichinellosis is a very rare disease and that non-specific symptoms predominate in the initial enteral phase of infection, the diagnosis proves to be difficult what often results in a loss of valuable time. Moreover, the incubation period which normally is five to 14 days may vary and can be extended to more than 40 days after infection, with intensity of clinical symptoms depending on infective dose and the immune status of the infected person. The E/S-ELISA is a suitable tool for the confirmation of diagnosis because this test provides a high sensitivity and specificity.

Generally, the period between clinical symptoms, diagnosis and notification of trichinellosis must be as short as possible in order to guarantee an optimal treatment of patients and to take all measures necessary to prevent further foodborne infections. However in these cases, the time between first clinical symptoms and first diagnosis was about five weeks and first notification about seven weeks (Fig. 1). Because of the fact that raw smoked sausage (Mettwurst) is generally consumed within the first five days after production and that there was a relatively long period between the time of infection and the tracing back measures (more than six weeks) it was not possible to obtain "Mettwurst" which had been produced at the questionable time. Probably, infected pork was mixed with non-infected pork or beef during processing to raw sausage or to minced meat. Depending on the intensity of mixing and processing, the number of infective larvae in food preparations may vary and finally result in an infection or not. Although a causative connection between both pork products might be expected, a common Trichinella source (i.e. the pork originated from the same producer) could not be confirmed. Epidemiological investigations indicated two simultaneous, but separate outbreaks. 


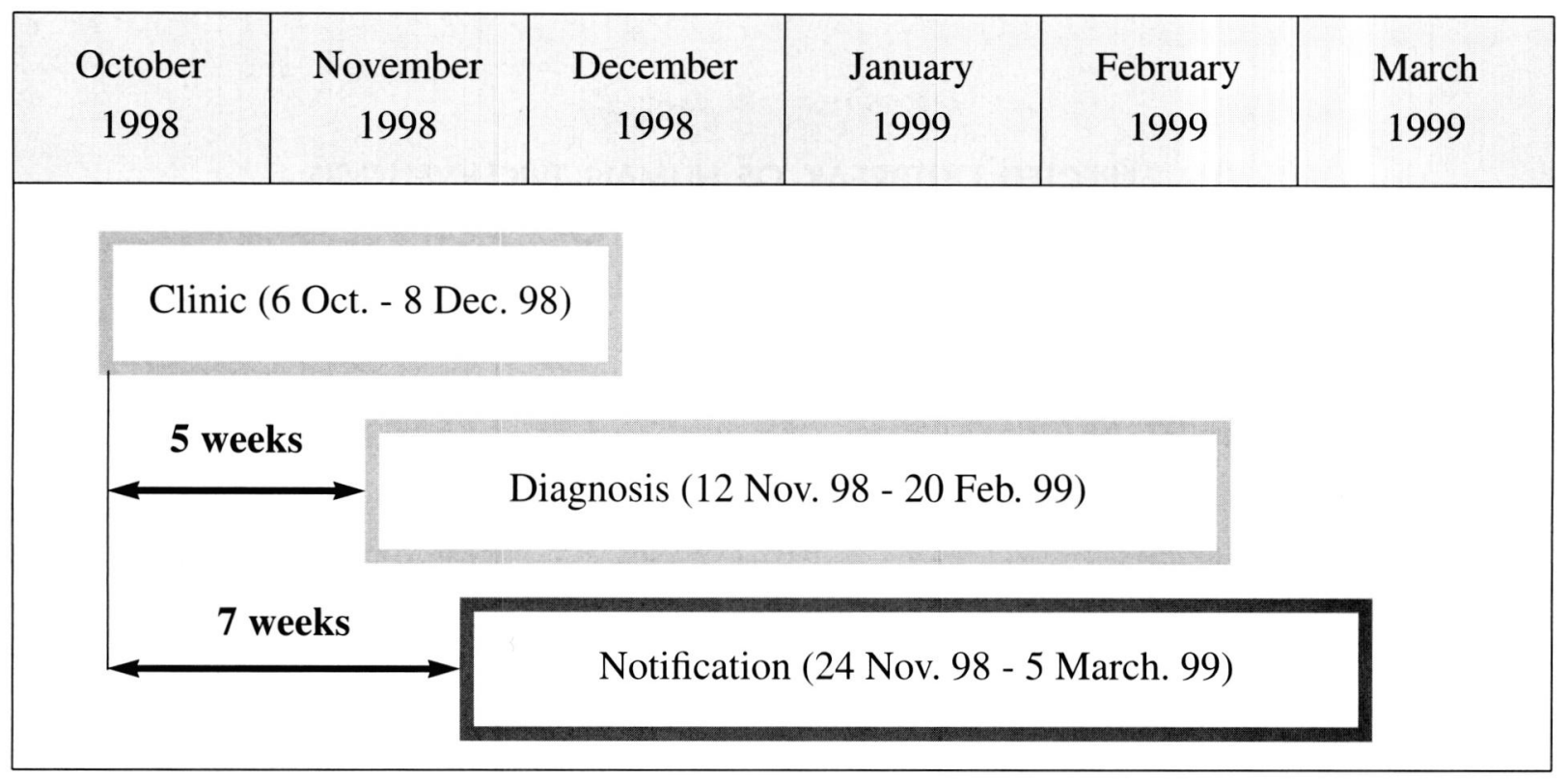

Fig. 1. - Periods between clinic, diagnosis and notification of Trichinella cases in NRW, 1998-1999.

The following conclusions were drawn:

- The examination of pork which may be a potential source for Trichinella larvae must be in compliance with the EU Directive 64/433/EEC.

- Methods prescribed for Trichinella inspection according to EU Directive 77/96/EEC must be conducted in a proper way. All laboratories should maintain a quality assurance system to ensure a high quality of inspection.

- Marking of animals and proof of origin for meat and meat products are necessary for tracing back measures.

- Consumers, physicians, health and veterinary authorities must be aware of trichinellosis as a probable health risk. In this context, special regard must be given to suitable preventive measures (e.g. inactivation of Trichinella larvae by cooking or freezing of meat products).

\section{REFERENCES}

Anders W., Kauer E. \& Sattler H. Epidemiologische Probleme eines Trichinose-Ausbruchs im Herbst 1967. Bundesgesundbbl., 1969, 20, 317-319.

DUPOUY-CAMET J. Is human trichinellosis an emerging zoonosis in the European community? Helminthologia, 1999, 36, 201-204.

European Economic COMmunity. Council Directive 64/433/EEC on health problems affecting intra-Community trade in fresh meat to extend it to the production and marketing of fresh meat. 1964, consolidated by Directive 91/497/EEC of 29 July 1991, Off. J. EC No L 268/69 and amended by Directive 95/23/EEC of 11 October 1995, Off. J. EC L 243.
European Economic Community. Council Directive 77/96/EEC of 21 December 1976 on the examination for trichinae (Trichinella spiralis) upon importation from third countries of fresh meat derived from domestic swine. 1976, Off. J. EC No L 26/67 of 31 January 1977. Amended by Decision 95/1/EC Off. J. EC No L 1 of 1 January 1995.

Rehmet S., Sinn G., Robstad O., Petersen L., Ammon A., Lesser D., David H., Noeckler K., Scherholz G., Erkrath K.-D., Pechmann D., Kundt R., Oltmans G., Lange R., Laumen J., Nogay U., Dixius M., Eichenberg J., Dinse F., Stegemann D., Lotz W., Franke D., Hagelschur P. \& Steigert M. Two outbreaks of trichinellosis in the state of Northrhine-Westfalia, Germany, 1998. Eurosurveillance, 1999, 4, 78-81.

StEIN H.A. Trichinose-Erkrankungen im Bitburger Raum (Eifel). Aus der Sicht der Humanmediziner des öffentlichen Gesundheitsdienstes. Öff. Gesundh.-Wes. 1983, 45, 532533.

Teuber J., Brehm H. \& Stumpf J. Zur Diagnostik der Trichinellosen unter besonderer Berücksichtigung eines modifizierten Immunfluoreszenztests. Immunität und Infektion, 1979, 6, 213-221. 